\title{
FACEMASKS THAT KILL VIRUSES
}

Lancaster based ViraCoat Ltd has submitted its FFP2 NR mask to rigorous testing to ISO18184 and EN149 compliance standards and gained certification that, within 30 minutes of contact, the SARS-COV-2 virus that causes COVID-19 was inactivated. This confirms that the coating is virucidal, meaning that it begins to kill viruses on contact and destroys SARS-COV-2 so that it cannot enter host cells. It is also antiviral, which prevents viruses from replicating, and antimicrobial, which prevents bacteria from developing, thus providing additional protection to the mask wearer.

As well as reducing transmission whilst being worn, the coating can significantly reduce the risk of contamination from handling the masks whilst putting them

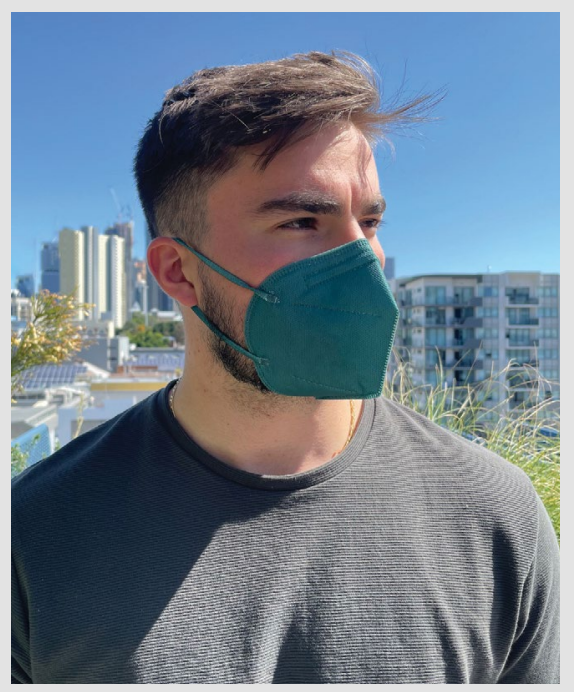

on, taking them off and disposing of them. Conventional masks only offer limited protection by filtering the air we breathe in and out, with considerable leakage around the edges. The ViraCoat masks are moulded and have an adjustable nose bridge for an optimal seal to prevent contamination by infectious aerosols - tiny virus particles that linger in the air and are now widely accepted as a source of coronavirus infections not screened by surgical style masks.

The ViraCoat coating has been demonstrated to have profound antiviral properties against not just SARS-COV-2 (including all new variants, such as delta variant) but also against Influenza (H1N1 seasonal flu strain), and bacteria (E.coli). The entire surface of the mask is covered, including the straps. The masks are a distinctive green colour to easily differentiate from standard PPE.

Jon Chadwick, CEO of ViraCoat's parent company ViraCorp, said: 'We are delighted that we have achieved ISO 18184 certification, which confirms our own testing through Lancaster University's world-class biomedical facilities. The level of protection we can offer healthcare workers and many others in hospitality, retail and travel, who risk exposure every day, is greatly enhanced and savings will result from fewer mask changes, plus we are reducing the number of masks ending up in landfill and our oceans'.

\section{HAPPY NEW ORAL HYGIENE}

For a healthier 2022, support your patients to improve their daily oral hygiene.

For a beautifully clean mouth, the highquality products from TANDEX are all they need.

To boost toothbrushing, recommend the TANDEX WOODI interdental brush for removing optimal debris. In a range of sizes, it will fit comfortably into different spaces; using the WOODI is a pleasure! It even has a handle made from responsiblysourced birchwood, so it can be recycled.

TANDEX produces preventive tools, including brushes and interspace brushes for all ages and dental situations.

A new routine is right for a new year and so is TANDEX.
For more information on Tandex's range of products, visit https://tandex.dk/.

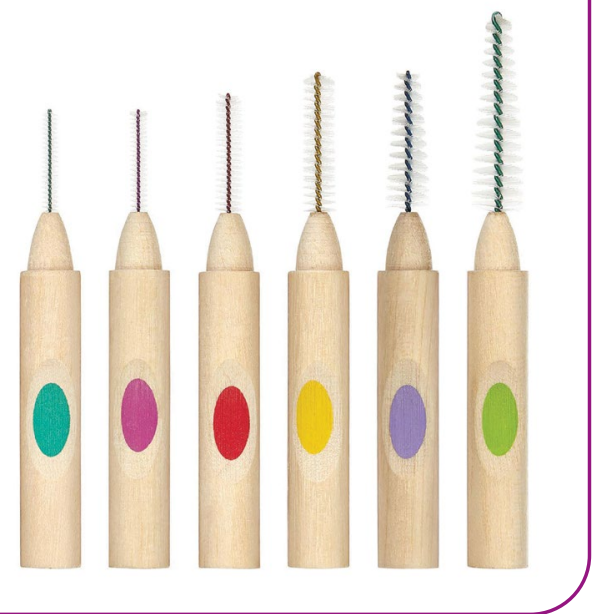

EXTRA PROTECTION AGAINST 'TWINDEMIC'

Experts are warning that we could soon be experiencing a 'twindemic' as Coronavirus and Influenza co-circulate.

Help defend your practice against this threat with the high-quality Steri-7 Xtra range of disinfectants from Initial Medical.

Effectively able to eliminate $99.99 \%$ of all pathogens including both Influenza and Coronavirus [tested against feline Coronavirus, a surrogate virus for Coronavirus], these solutions are safe to use throughout your practice, are delicate on equipment and provide lasting protection. Formulated with Reactive Barrier Technology, the whole range prevents the recolonisation of pathogens on treated surfaces for up to 72 hours as long as the product isn't wiped away after application.

Boost your defences and keep your practice safe by contacting Initial Medical to find out more.

For further information visit www. initial.co.uk/medical or Tel: 08708504045 .

\section{OVER 100,000 STERILISERS PRODUCED}

W\&H has been designing and fabricating sterilisers for dental professionals since 1999. All W\&H sterilisers are created by a team of experts at W\&H's Sterilisation Centre in Brusaporto, Italy, perfectly combining style and elegance with efficiency and practicality.

Today, W\&H offers an impressive range of solutions with the Lisa, a fully automated B type steriliser, the Lara and the Lyla S type with innovative upgradeability options. The range of sterilisers available are designed to meet the requirements and preferences of any dental team.

Why not see for yourself how W\&H has continued to invest in research and development, allowing it to use its experience of 100,000 sterilisers to produce tailored solutions ideally suited to the needs of individual practices?

The exceptional portfolio from W\&H with innovative functionalities offers top quality decontamination solutions for all.

To find out more visit www.wh.com/ en_uk, call 01727874990 or email office. uk@wh.com. 